\title{
Prediction of available power being generate in small hydropower system at Sungai Perting Bentong Pahang
}

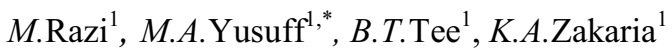 \\ ${ }^{1}$ Faculty of Mechanical Engineering, Universiti Teknikal Malaysia Melaka, 76100 Durian Tunggal, \\ Melaka, Malaysia
}

\begin{abstract}
Tremendous studied had been conducted on small hydropower system based on run-of-river schemes as an alternative renewable energy. Small hydropower system can be classified based on electricity generated between $1 \mathrm{MW}$ to $10 \mathrm{MW}$. This system is normally being applied in rural area for providing the consumer electricity demand. Basically the researches to date are more focusing on the large scale of hydropower rather than the small scale hydropower technology. Therefore, this study is aimed to focus on predicting the available power generated by the small hydropower system specifically for the river stream in peninsular Malaysia. The water flow rate is measured by using ultrasonic level sensor located at the intake of the small hydropower system. The water flow rate is important data to be used in predicting the power output of the power house. The result shows that, the power outputs are depending on the fluctuation of water flow rate and the electricity being generated is more than $1 \mathrm{MW}$. This finding can be used as the benchmark for daily and monthly monitoring process of the system efficiency or target output.
\end{abstract}

\section{Introduction}

Peninsular Malaysia is blessed with an abundance numbers of water resources and due to the extreme topography of the mountain; most streams have very high slopes. This combination of stream flow and high stream gradient or slope is ideal for the run-of-river hydropower development. This kind of small hydropower development has the least environmental impact and is generally less capital intensive than typical hydropower plants built in conjunction with high dams and large amounts of water storage [1]. Besides, small hydropower system is one of the significant renewable energy alternatives that have been greatly developed in the past few decades due to its small scale, lower investment, and the promotion of local economic development especially for rural application in generating electricity [2-6].

\footnotetext{
* Corresponding author: mohd.asri@utem.edu.my
} 
The small hydropower system can be developed in a reservoir or run-of-river type. In For run-of-river type, there is no water storage for power generation, but the water is diverted from the main river by weir. For small capacities of hydropower system, run-ofriver types are highly recommended. A typical run-of-river small hydropower system for electricity generation is consisted of the following basic components: water intake structure (e.g., weir and settling tank), penstock, turbine, mechanical power transmission system to generator, generator, and electricity transmission system to load centers, and control system [7]

The power production of small hydropower plant is a dynamic process which indicates the maximum generation capacity under certain meteorological and hydrological conditions. It is also easily being influenced by hydrology, climate, and installation capacity. Therefore predicting the power production of a small hydropower system is a non-linear and multi-factor complicated problem. Due to the less value of the installed capacity in a single plant, it is hard to predict its power production along with strong uncertainty and fluctuation [4]. Besides, the important of predicting the production output in a small hydropower plant is to maintain its sustainability development. To obtain the power production estimation, the value of the net head and water flow of the system are required. Net head is difference between the gross head and the losses due to friction and turbulence in piping, while the water flow is the quantity of water in cubic meter per second [8].

The power production of small hydropower plant shows great spatiotemporal diversity, and thus, it is difficult to establish a commonly used model. These data can be served as a source of information for the model development and to build a procedure to simulate the operation of hydrological and hydraulic systems that can be used for optimizing the marketing of the renewable energy technology. The power production depends a lot on the environmental conditions for example, precipitation, weather changes and etc. In Malaysia generally, small hydropower plant based on run-of-river types is less implemented, therefore it has some challenges in predicting the power production and becoming complex task. So, prediction of performance output is necessary in providing adequate information for further research. This paper aim to study the power generated by small hydropower system based on run-of-river located in Peninsular Malaysia, specifically at Sungai Perting, Bentong, Pahang.

\section{Experimental setup}

The present experiment aims to study the power output generated by the $5 \mathrm{MW}$ gridconnected small hydropower plant in Sungai Perting, Bentong, Pahang with net head of $159.6 \mathrm{~m}$. In order to obtain the result, ultrasonic level sensor was installed to measure the water flow rates $\left(\mathrm{m}^{3} / \mathrm{s}\right)$ of the river which is crucial variable needed in calculating the power generation by the small hydropower system. The Signature Flow Meter which is connected through TIENET 310 Ultrasonic Level Sensor was specially designed for open channel flow monitoring application. The flow meter sensor was installed at water intake of the river for each pairs of the water channel. This device is a non - contact liquid level measurement work by measuring the time interval between the transmissions of the river surface sound pulse to the sensor. The function of signature flow meter is to process the data obtained from the level sensor in terms of water flow rates numerical values. In this research, the data of water flow rate were used as crucial parameters to calculate the power prediction that were obtained hourly for whole day in January 2016 which is equivalent to 744 hours. Figure 1 (a) shows Ultrasonic Level Sensor and Figure 1 (b) shows Signature Flow Meter. 


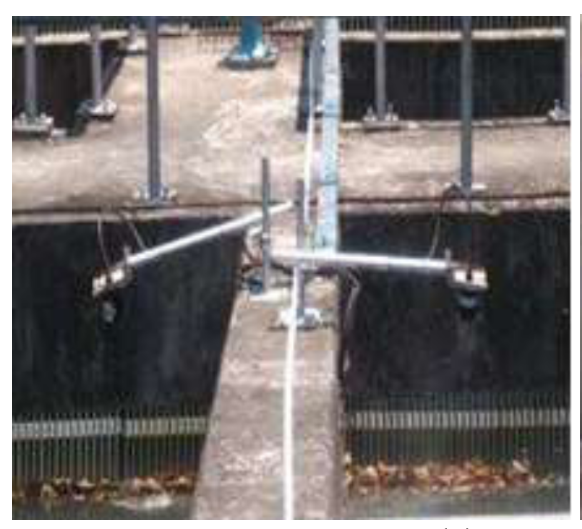

(a)

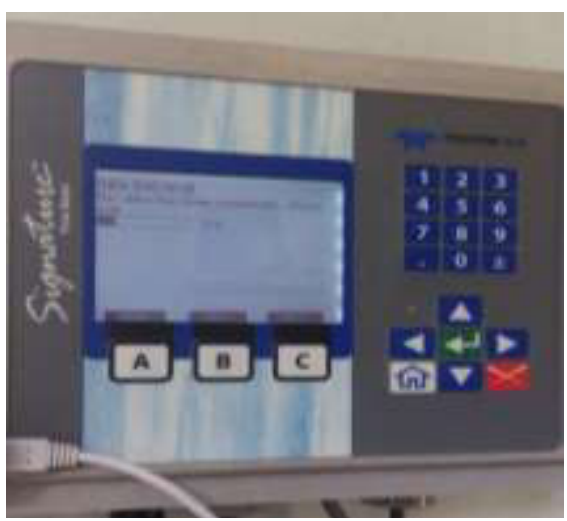

(b)

Fig. 1. Equipment used in this experiment.

\section{Results and discussion}

Statistical analysis will be performed in evaluating the result. The water flow rates obtained were in form of continuous random variables. Power generated by the small hydropower system can be calculated by using Equation (1) where, $\rho\left(\mathrm{kg} / \mathrm{m}^{3)}\right.$ is a density $1000 \mathrm{~kg} / \mathrm{m}^{3}, g$ $\left(\mathrm{m} / \mathrm{s}^{2}\right)$ is the acceleration due to gravity $9.81 \mathrm{~m} / \mathrm{s}^{2}, \mathrm{Q}\left(\mathrm{m}^{3} / \mathrm{s}\right)$ is the flow rate, and $\mathrm{H}(\mathrm{m})$ is the net head available at the inlet to the turbine and $\eta$ is the overall energy conversion efficiency [9]. The overall efficiency for small hydropower system electricity generation is lower $(<80 \%)$ than for mechanical power supply system because of generator losses in the former [10]. Therefore, in this analysis, the net head and overall efficiency used are 159.6 $\mathrm{m}$ and $80 \%$ or 0.8 respectively.

$$
\mathrm{P}=\rho g H Q \eta
$$

Based on the calculation by using Equation (1), the average power output generated in January 2016 was 4.25 MW. Figure 2 shows the scattered plot for exploited power in the small hydropower system. Based on the graph, the data are randomly distributed. The maximum and minimum value was spotted away from the overall linear pattern distribution and basically the exploited power fluctuation is directly proportional to the flow rates of the stream as shown in Figure 3. The fluctuations in the graph are caused by wet and dry weather which also influenced the increment of precipitation [11]. The level of precipitation will be lesser during dry weather compared to wet weather.

Figure 4 shows the probability density function for the generated power output. The probability density function is a curve that represents the probability distribution of a continuous random variable of the generated power output. The curve indicates the regions of higher and lower probabilities for the random variable values. From the graph, it shows that the probability of the generated power is denser between 2.0 MW - 5.0 MW. It means this area of distribution it has the highest probability of the power generated in MW by the system. The graph was skewed to the left and the mean value was located to the left of the peak value. The peak value of the graph shows the mean of the power generation from the small hydropower system which is $4.25 \mathrm{MW}$. 


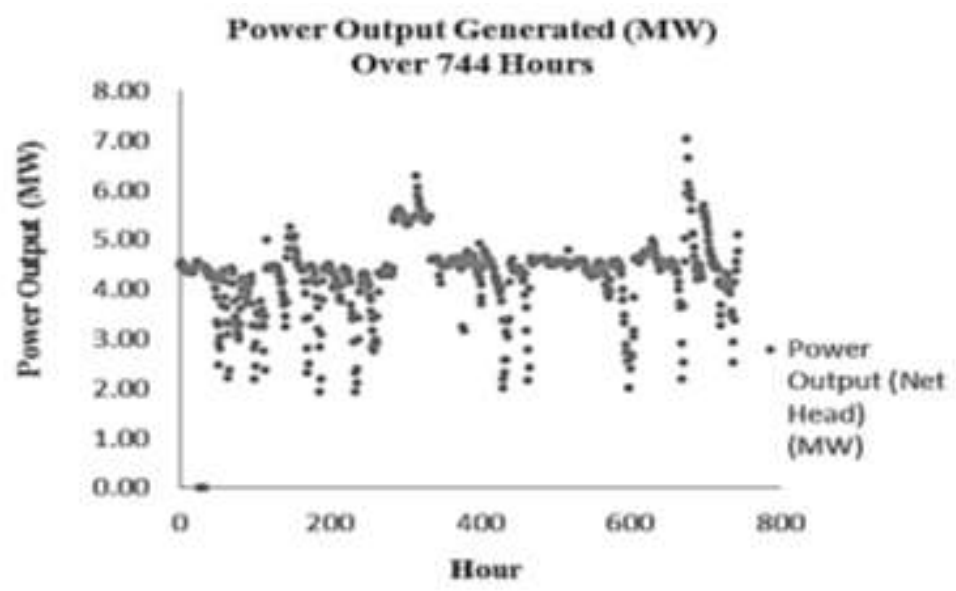

Fig. 2. Scatter Plot of Generated Power Output (MW) in January 2016.

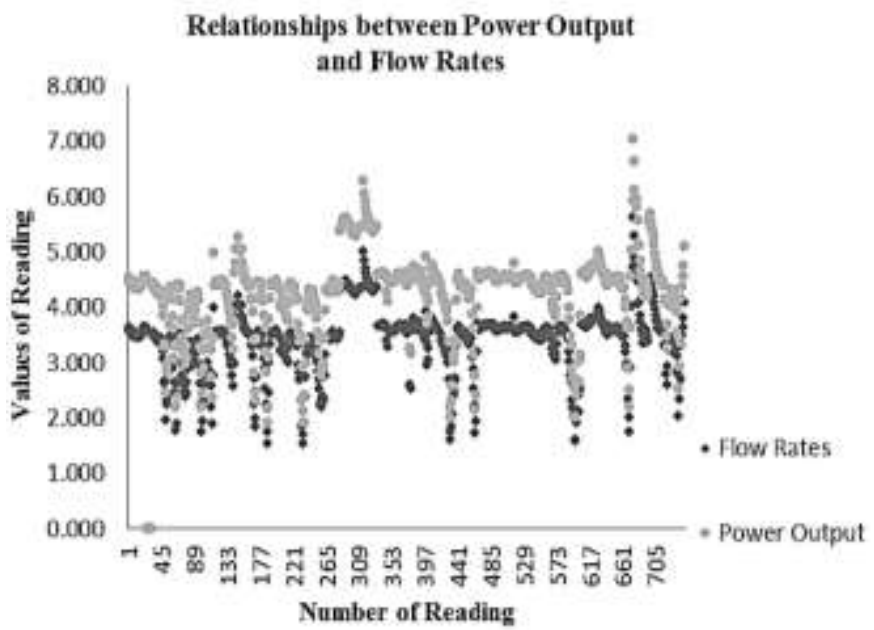

Fig. 3. Relationship between Power Generation (MW) and Water Flow Rates $\left(\mathrm{m}^{3} / \mathrm{s}\right)$ in January 2016.

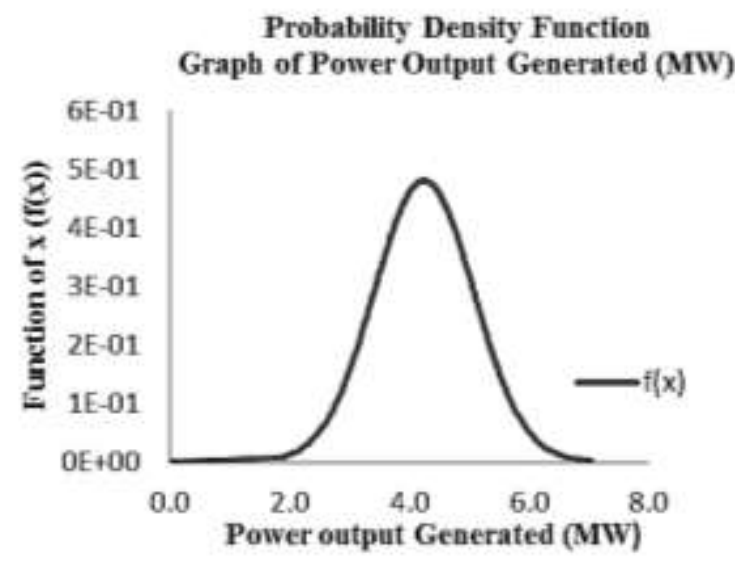

Fig 4. Probability Density function for Generated Power Output (MW). 


\section{Conclusions}

This paper provides adequate information on predicting power production by small hydropower system based on run-off-river in Peninsular Malaysia Rivers. Besides, the prediction of power production for such small power plants is an essential tool to ensure ongoing power supply for user demand, to plan for reserve power supply and transaction between power plants especially in rural area application. The power production of small hydropower can be ranged from few $\mathrm{kW}$ until thousands of MW and much reliable as a clean energy sources compared to other types of power plant. In this study, the mean value of generated power obtained in January 2016 was $4.25 \mathrm{MW}$. The highest production value was around $7 \mathrm{MW}$ and the least value was around $2 \mathrm{MW}$. The current findings from this work is hoped to be one of information sources in designing or choosing potential sites for small hydropower plant installation. Those present and further findings will provide mass benefit to the rural electrification generation in fulfilling the increasing energy demand.

The authors would like to thank Ministry of Higher Education of Malaysia and Universiti Teknikal Malaysia Melaka (UTeM) for providing support and financial assistance through the Fundamental Research Grant Scheme award (FRGS/2/2014/TK06/FKM/03/F00235).

\section{References}

1. Heitz, Leroy F., Shahram Khosrowpanah. "Prediction of Flow Duration Curves for Use in Hydropower Analysis at Ungaged Sites in Pohnpei," FSM. Water and Environmental Research Institute of the Western Pacific, University of Guam, (2010)

2. Yuksel, I. "As a renewable energy hydropower for sustainable development in Turkey,” Renew. Sustain. Energy Rev. 14, 3213-3219, (2010)

3. Dudhani, S., Sinha, A.K., Inamdar, S.S. "Assessment of small hydropower potential using remote sensing data for sustainable development in India," Energy Policy, 34, 3195-3205, Water 2015, 7 4819, (2006)

4. Bakken, T.H. Sundt, H. Ruud, "A Development of small versus large hydropower in Norway comparison of environmental impacts," Energy Procedia, 20,185-199, (2012)

5. Bøckman, T.; Fleten, S.E.; Juliussen, H.J. "Investment timing and optimal capacity choice for small hydropower projects," Eur. J. Oper. Res, 190, 255-267, (2008)

6. Kosnik, L. "The potential for small scale hydropower development in the US," Energy Policy, 38, 5512-5519, (2010)

7. Kaunda, Chiyembekezo S., Cuthbert Z. Kimambo, and Torbjorn K. Nielsen. "Potential of small-scale hydropower for electricity generation in Sub-Saharan Africa." ISRN Renewable Energy (2012)

8. Kosa Preeyaphorn, Thanatchai Kulworawanichpong, Rerkchai Srivoramas, Avirut Chinkulkijniwat, Suksun Horpibulsuk, and Neung Teaumroong. "The potential microhydropower projects in Nakhon Ratchasima province, Thailand." Renewable Energy 36, no. 3, 1133-1137, (2011)

9. Kaunda, C. S., Kimambo, C. Z., Nielsen, T. K. "Potential of small-scale hydropower for electricity generation in Sub-Saharan Africa". ISRN Renewable Energy, (2012).

10. Paish, O. Micro-hydropower: status and prospects. Proceedings of the Institution of Mechanical Engineers, Part A: Journal of Power and Energy, 216(1), 31-40 (2002).

11. Sarkkula, J., et. al "Origin, fate and role of Mekong sediments. Detailed Modelling Support Project, Mekong River Commission, Vientiane, Laos PDR”, (2010). 
12. Li G., Liu, B. Li, S.Z. "An overview of large scale small hydropower in Yunnan Power Grid: situations, challenges and measure," In Proceedings of World Environmental and Water Resources Congress, Cincinnati, OH, USA,(2013)

13. Amcorp Properties Berhad, Amcorp Perting 5MW Mini Hydro Power Plant. 